\title{
Wage Dips and Drops around First Birth
}

\author{
Mette Ejrnces $\dagger$ and Astrid Kunze†† \\ 30. January 2002
}

\begin{abstract}
:
Germany has been claimed to be one of the countries with the most generous maternity leave and parental leave legislation. The success of such policies can be evaluated in terms of female labour force participation rates, wage effects and children's outcome. We use a rich longitudinal data set to disentangle the wage effects around first birth. Descriptives reveal an average real wage drop of 10 to 20 percent per year of parental leave for 1980 to 1995. A model consistent with a loss is a human capital theory story that predicts human capital depreciation during out of work periods. Yet, the size of the loss appears surprisingly high within a parental leave system that functions as a safety net. In order to pinpoint what drives the loss and to draw inference about the parental leave system we take into account the potential correlation of the duration of individual interruption due to parental leave with other unobserved individual specific factors and non random sample selection. We exploit the panel structure of the data for identification as well as policy changes of the maximum duration of parental leave that has been extended from 6 months in the mid 80s to 3 years in the 90s.
\end{abstract}

JEL codes: C23, J13, J31.

Key words: empirical labour economics, wage equation, panel data, instrumental variable estimation.

† University of Copenhagen, Mette.Ejrnes@econ.ku.dk, †† IZA, Bonn, kunze@iza.org. 


\section{Introduction}

Germany has been claimed to be one of the countries with the most generous maternity leave and parental leave legislation. However, the success of such policies can be evaluated in terms of children's outcome, female labour force participation rates and wage effects. Most of the previous studies concerning maternity leave are concerned with the two first topics. In this paper we look at partial wage effects of interruptions due to maternity or parental leave. For a number of reasons it is interesting to look at wage effects. First, the market wage is an important determined of the participation decision. Second, short run negative effects on wages through parental leave may have long run implications on future wages, risks of poverty, also in case of divorce, for example, pensions and the wealth of children.

Studying the German case in this context turns out to be particularly interesting: On the one hand, in international comparative studies $^{1}$ on parental leave policies the German system is claimed to be one of the most generous and family friendly ones. On the other hand, descriptives reveal an average real wage drop of 10 to 20 percent per year of parental leave for 1980 to 1995. This applies to full-time workers and, hence, excludes the case of switching from full time to part time work, as it is often the case. A model consistent with a wage loss is a human capital theory story that predicts human capital depreciation during out of work periods. Still, the size of the loss appears surprisingly high within a parental leave system that functions as a safety net.

To motivate our analysis we start by presenting empirical evidence of wage effects for women around the time for the first birth. To do this we use the German IABS sample ${ }^{2}$ from which we have selected a sample of young women who all

\footnotetext{
${ }^{1}$ OECD (1995), OECD (2001).

${ }^{2}$ Details about the sample will be provided later.
} 
Figure 1:

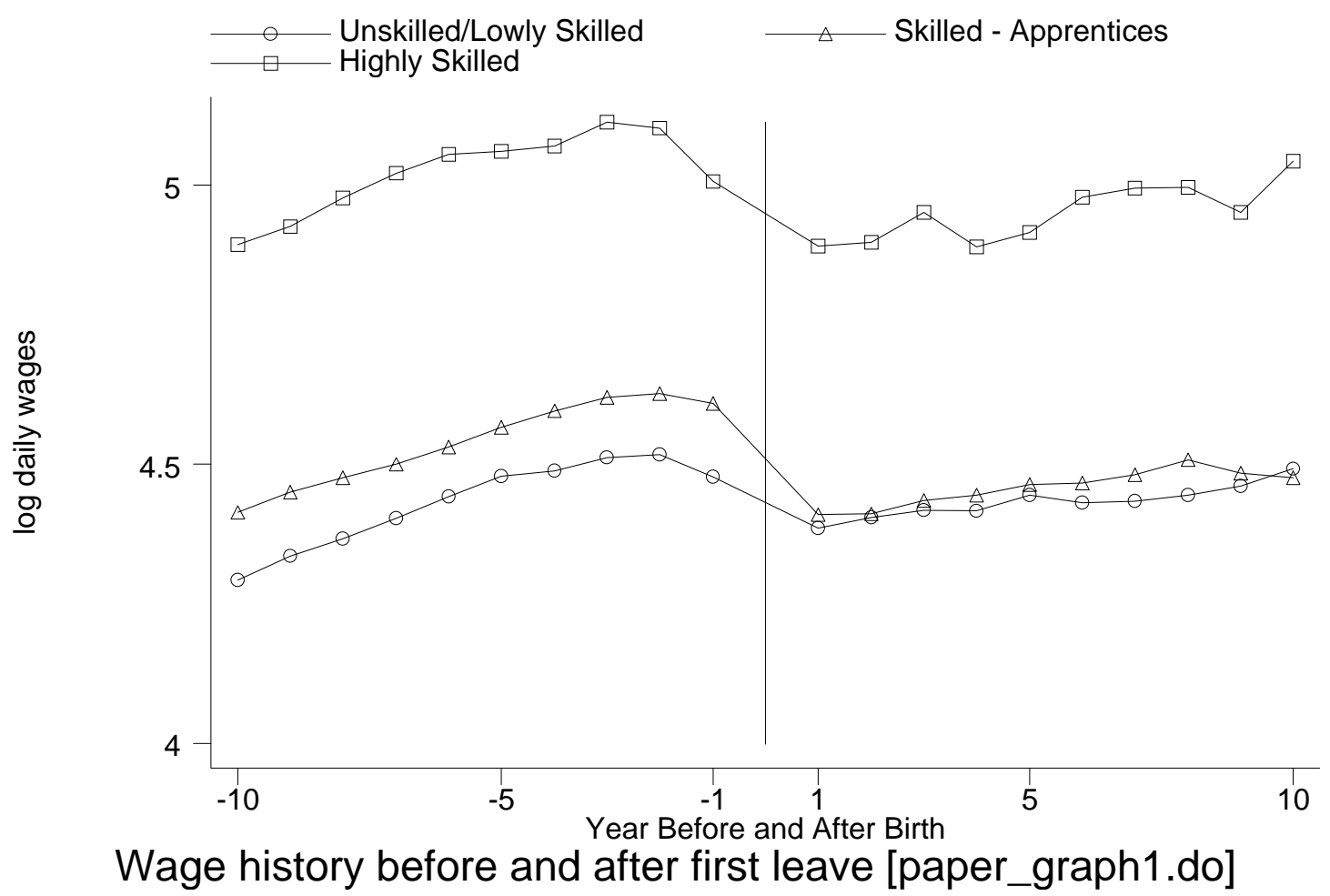

are observed with an interruption of the labour market career due to a maternity leave spell. To highlight the wage effects around first birth we have sorted the data according to years since the interruption. In Figure 1, mean wages ${ }^{3}$ are shown for three education groups: Unskilled/Lowly Skilled, Skilled/Apprentices and Highly Skilled. The vertical line represents the year in which maternity leave is taken: the negative numbers on the $\mathrm{x}$-axis refer to the number of years before the first birth while the positive numbers on the x-axis refer to number of years after the first birth. As the graph clearly points out there are huge wage effects around the first birth.

\footnotetext{
${ }^{3}$ The wages are defined as the logarithm of daily wages. Only wages corresponding to full time employment are included.
} 
This rises three main issues that we address in this study. First, before birth it is worthnotice that for all education groups mean wages start to decline two years before first birth. So what we see here is actually a dip in the wage-profile just before female workers take maternity leave. ${ }^{4}$ The graph indicates that the dip is most pronounced for those with a graduate degree. There might be many reasons for this dip, and one of the goals of this paper is to scrutinize what is going on immediately before the birth. Second, wages are substantially lower after maternity leave. Even though this finding may be highly sensitive to selection into work after giving birth, the selection in this case seems to result in understating the loss because one may expect that those who are offered a very low wage after giving birth are less likely to take the job and return to work. However, this issue will be more carefully examined in the paper, where we also attempt to decompose the loss due to different factors i.e. the duration of maternity leave and individual characteristics. Third, it seems that the earnings profile is flatter after giving birth than before. However, it is difficult to tell whether this is purely due to the selection process back to work or whether the profile actually is flatter than in the phase before the interruption. This problem will be also addressed in the subsequent analyses.

We assume the human capital theory model..$^{5}$ As a framework for our analysis of wage effects of women around the first birth, we use an approach very similar to the approach by Jacobson, LaLonde and Sullivan (1993) who examined earnings losses for dismissed workers. They found that the earnings effects can be labelled as: the dip, the drop and the recovery. In this paper we will adopt their vocabulary and the analysis is structured along the three life cycle phases: the pre-birth

\footnotetext{
${ }^{4}$ The fact that wages/earnings drop prior to an interruption is also found in other branches of the literature; for interruptions due to training see Ashenfelter (1978) and for interruptions due to displacement see Jacobson, LaLonde and Sullivan (1993).

${ }^{5}$ Becker (1964).
} 
phase, that is the dip prior to the interruption, the immediate before and after birth phase, that is the drop around the interruption, and the after birth phase, that is the recovery after the interruption. To investigate wage growth and wage losses we specify and estimate wage growth equations for each phase. This approach has the advantage that specific mechanisms that lead to increasing and decreasing wages in each stage can be traced. The key parameters are the return to work experience and the loss from interruption. In order to recover the structural parameters, taking into account unobserved heterogeneity and non-random sample selection, we make use of the panel structure of the data that allows to use lagged variables as instruments as suggested by Arellano and Bond (1991). Furthermore, we exploit policy changes that increased the maximum duration of parental leave several times. It was 6 months in the mid 80 s and 3 years in the 90s.

For the empirical analysis we use the $\mathrm{IABS}^{6}$ that is available for 1975 to 1995 . The IABS is the equivalent social security data and, therefore, contains particularly reliable information on wages and work histories, for our sample of females. From this data set we extract a sample of young females, age 20 to early 40s. All of them are followed over their career from the beginning onwards. This data sample offers particular advantages for this type of analysis. First, we can observe a large number of workers over a long period of time in the labour market that includes the first interruption due to parental leave. ${ }^{7}$ For more than 11,000 females we observe before first birth wages, and for approximately 6,500 we observe wages before and after birth. In addition, we observe females without an interruption which we make us of in order to define a control group. Second, we can measure

\footnotetext{
${ }^{6}$ IABS abbreviates Institut für Arbeitsmarket und Berufsforschung Sample.

${ }^{7}$ In the text we use first birth alternatively to the expression first parental leave, maternity leave.
} 
actual work experience acquisition before and after the interruption as well as the duration of the interruption due to parental leave. ${ }^{8}$ This is because labour market histories are observed from the beginning and status can be distinguished in great detail. In addition, controls for age, firm and occupation are available. Third, multiple spells enable us to construct lagged variables that can be exploited for the moment conditions. The data, however, is not without limitations. Main shortcomings due to the lack of hours of work will be compensated by usage of supplementary survey data that we describe in the main text of the paper.

The paper is organised as follows. In section 2, a short review of the existing literature is given. Section 3 describes institutional features of the maternity and parental leave schemes in Germany. Section 4 contains a data description and in section 5 the econometric model is stated. Section 6 discusses the estimation results and finally, in section 7 , we conclude.

\section{Previous evidence}

Most of the studies examining effects of maternity leave and children have been concerned with the effects on labour supply and the timing of births. Only a few empirical studies investigate the impact of maternity leave and having children on the individual wage process. The most common approach to analyse the wage effect of having children has been to estimate a child penalty. That is comparing the wages of women with children to those of childless women when controlling for observed characteristics. The difference in wages is often called the family gap. Although the evidence is mixed, most studies find a significant child penalty. A significant child penalty is found for the US and the UK (see Waldfogel (1998)), for UK (see Joshi, Paci and Waldfogel (1999)) and for Canada (see Phipps, Burton

\footnotetext{
${ }^{8}$ We provide more details on how we measure parental leave duration in the main text.
} 
and Lethbrigde (2001)). On the other hand no evidence of a child penalty is found for Denmark (see Datta Gupta and Smith (2001) and for Sweden (see Albrecht et al., 1999) $)^{9}$.

In the literature different hypotheses for the existence of a child penalty have been offered. One potential explanation for lower wages of mothers is that women with children have interruptions of their labour market career due to a maternity leave spell. The interruption will result in less work experience of mothers compared to childless women. In Waldfogel $(1997,1998)$, this problem is addressed by using actual experience instead of potential experience, but she still finds a significant child penalty for women. Furthermore, it has also been suggested that interruptions could have negative effects on earnings. These negative effects can be explained by depreciation of the human capital (Mincer and Polachek (1974)). Albrecht, Edin, Sundstrom and Vroman (1998) analyse the effect of an interruption on subsequent earnings using Swedish data. They find negative effects of an interruption, and, furthermore, they find that different effects of different kinds of interruptions. Interruptions due to unemployment cause greater losses than interruptions due to maternity leave and child care. In Kunze (2001) negative effects of interruptions are found for young women in Germany. The effect for interruption due to maternity leave is greater than interruption due to unemployment.

A second hypothesis explain the child penalty by heterogeneity among women. The underlying idea is that women have different abilities, that is often unobserved, or productivity and these characteristics may be correlated with the fertility. In Lundberg and Rose (2000), they find that mothers prior to their first birth earn nine percent less than women who remain childless. To deal with this aspect most of the studies apply a fixed effects estimator in order to remove unobserved

\footnotetext{
${ }^{9}$ For more details on these studies see Table A2.1 in Appendix 2 at the end of this paper.
} 
characteristics like taste and ability.

The choice of sector or type of job has also been suggested as a possible determinant of the child penalty. If women with children choose to work in sectors or types of job which are in general characterised by lower payment, yet perhaps also by a more family friendly working environment, this will lead to a child penalty. In Joshi, Paci and Waldfogel (1999) the child penalty is examined for two cohorts of British women. Their results show that mothers have lower wages than childless women. By using the Oaxaca decomposition they find that part of the family gap can be attributed to part time employment. Yet, even among full time employed women there is evidence of a child penalty. Datta Gupta and Smith (2000) exploit this hypothesis by estimating the effect for the private and public sector separately. They find quite surprisingly that there actually is a positive effect of having children in the public sector. This issue is also the topic for a recent study by Nielsen, Simonsen and Verner (2001). They examine the wage effects of career interruption in a model where the choice of sector is endogenous. By using data on Danish women, they find small wage effects in the public sector while there are no effect in the private sector.

A closely related explanation is that job-mobility of mothers is relatively low. If mothers are less likely to search for new jobs because of high search costs, for example, they may remain in jobs that are a bad match and more slowly improve the quality of their job match. This leads to lower earnings compared to similar childless women. Since the fertility period often clashes with the early career, the loss due to motherhood might depend on the timing of the children in relation to the labour market career. However, Waldfogel (1998) and Phipps, Burton and Lethbridge (2001) find that returning to the same employer after the maternity leave actually has a positive effect on wages, but this might be because staying with the same employer actually acts as a kind of insurance against income 
loss. Furthermore Waldfogel (1998) finds that the size of wage loss due to taking maternity leave depends on whether the woman was covered by a maternity leave scheme.

Fifth, a hypothesis to explain the child penalty is that women with children invest less effort and are, hence, less productive. ${ }^{10}$ This hypothesis is investigated by Phipps, Burton and Lethbrigde (2001) who argue that the more time women spend on housework and child care the less energy they have for their labour market career. By including numbers of hours spent on unpaid work in the estimation they find that the child penalty declines, but remains significant. Related to this hypothesis is the discrimination hypothesis, which suggests that employers pay women with children less because they think they are less productive.

The final hypothesis that we discuss in this paper concerns the fact that fertility could be endogenous to the wage process. The idea is that women who are not promoted or do not succeed to make a good match may instead choose to have a child or that women who are successful in their labour market career might postpone having children or choose not to have children. To our knowledge this hypothesis has not been examined yet.

\section{Institutions and policy changes}

\subsection{The German maternity and parental leave reforms}

Germany has one of the most generous parental leave and benefit policies. ${ }^{11}$ For the period 1975 to 1995, two laws are most relevant for the description of the maternity and parental leave system. These are the maternity protec-

\footnotetext{
${ }^{10}$ Becker (1985).

${ }^{11}$ For an international comparison see Blau and Kahn, 1995.
} 
tion law (Mutterschutzgesetz) and the federal child-rearing benefit law (Bundererziehungssgeldgesetz). Additionally, the protection law against wrongful dismissal Kündingungsschutzgesetz applies.

Only since 1979 have employed mothers been eligible for maternity leave and benefits. ${ }^{12}$ Before this time, maternity protection in the form of forbidding work has had a long history, though, going back to trade regulations that took effect in 1878. From 1979 to 1985, legal regulations were restricted to mothers taking leave, while since 1986 fathers have been able to take legally protected leave as well. For fathers, still, taking parental leave is the rare exception; in 97 percent of all cases it is the mother who takes parental leave.

The term protected leave implies that the parent has the option to return to the job, i.e. a comparable job, held before pregnancy of the mother; hence, the employer must hold the job available until the protected leave expires and cannot fire the worker during this period. Usually during the first six months, compensation may be paid in form of benefits by the health insurance, by the state or in form of wages paid by the firm. Afterwards the employer-employee relation is on hold without any claims for wage payments to the employee.

$>$ From 1980 until 1985, regulations were based on the maternity protection law ("Mutterschutzgesetz"). It contains four main regulations: First, women cannot be dismissed during pregnancy and until 4 months after delivery. Second, mothers must not work 6 weeks before and 8 weeks after delivery (the maternity protection). Third, mothers are entitled to 4 months protected maternity leave after the maternity protection period. Fourth, mothers are entitled to 6 months of maternity benefits after childbirth. In 1986 the federal child-rearing benefit law ("Bundeserziehungsgeldgesetz") took action which replaced the concept of ma-

\footnotetext{
${ }^{12}$ For comparison, in the U.S. the first law affecting parental leave was introduced much later. It is the Family and Medical Leave Act of 1993.
} 
ternity leave by the concept of parental leave. Durations of maternity or parental leave, are summarised in Table 1.

Key policy changes during the 80s until the mid 90s can be summarised in three points: First, in 1986 the switch from a purely maternity leave system to a parental leave system took place. Second, in 1991 protected leave was extended to three years. Third, maternity and parental leave benefits changed with respect to the amount and eligibility.

Until 1986, in order to be eligible for maternity benefits mothers had to be employed (and not self employed). Since 1986, all mothers and fathers can claim benefits; also not-salaried parents.

In the federal child-rearing benefit law, as well as in subsequent amendments of the law, the period of protected leave was sequentially extended and, almost accordingly, the period of entitlement to benefits too. They are listed in Table 1. For instance, from 1986 to 1988 the protection period was extended to 8 months, and thus, entitlement to benefits to 10 months, which includes two months of maternity protection. However, eligibility for full duration of benefits based on the child-rearing benefit law is means tested.

These policy changes are particular useful for identification of wage effects. First, one can assume exogeneity to the wage process. This is particularly the case because law changes apply to children born after a certain date in the near future. Hence, also given the imperfect expectation about having children, one may claim that individuals will not change their behaviour regarding having children because of an expected extended parental leave. Although parents can change the duration of the parental leave in the range of the maximum leave granted by law at the time of birth of their children, they cannot take directly advantage of the policy change. ${ }^{13}$

\footnotetext{
${ }^{13}$ However, one may argue that they can plan to have a second - further - child due to
} 
Before 1986, benefits ranged from 3.50 to 25.00 German Mark per day ${ }^{14}$. The amount depends on the income during the previous three months before delivery of the child. If the average income was higher than benefits paid, the mother was entitled to an employer supplement during the maternity protection period, i.e. two months after birth of the child, equal to the difference. From the third month after birth of the child onwards the maximum was 17.00 German Mark per day. Since 1986, benefits can be claimed for longer, but depend then on the annual net family income two years before birth of the child. Benefits are reduced on a sliding scale basis. ${ }^{15}$

Under the presumption that we have information on household income, one may make use of the policy changes regarding benefits too. However, they are hard to disentangle. Furthermore, one may note that replacement rates are only high during the first six months of maternity leave. Yet the majority of women taken longer leave than that. Effects of benefit receipt after the sixth month may only be crucial for low income parents, or single parents. According to the Reichsversicherungsordnung $(\S 200, R V O, 60)$ maternity benefits are based on net monthly earnings that are calculated as gross monthly earnings minus allowances (gesetzliche Abzüge).

As described above the maternity leave system in Germany was subject to several reforms during the 80 's. We briefly summarise other studies analysing the reforms in the maternity leave system. Most of these studies have been concerned with the reforms' impact on labour force participation for women.

Ondrich et al. (1999) model the decision to return to work after having children improved legal framework. We cannot take this into consideration given our data.

${ }^{14}$ These correspond to the 600 German Mark per month paid by the health insurance.

${ }^{15}$ No benefits are paid if the family income is greater than 29,400 German Marks per year, or, in case of single parents, if the yearly income is greater than 23,700 German Marks. Each additional child increases the benchmark by 4,200 German Mark. 
and evaluate the effect of the extensions of the duration of parental leave on the decision to return to work. German law guarantees a job within the firm of employment before leave. However, they assume that the probability of replacement increases with the duration of maternity/parental leave. Hence, the employer may decide to place the woman after return on a job position on a lower scale pay; since they have hired someone else for her former position.

In Ondrich et al. (1996), they find that during the leave mothers are less likely to return to work the longer is the time left in the leave protection period; however, this result cannot be attributed generally to high levels of maternity benefits. When the leave protection period ends, mothers with strong labour force attachment return to their jobs. There have been other studies making use of the policy changes in German parental leave (Klein and Braun, 1995; Gustafsson, et al., 1996). They include dummies in hazard rate models for the years of the policy change. They are interested in explaining differences in participation rates.

\section{The data}

We use the IAB employment sample (IABS) ${ }^{16}$ for West-Germany that is available for the period 1975 to 1995 and is an administrative event history data set. The IABS is a 1 percent random sample drawn from the event history data file of the social security insurance scheme, the employment statistics, collected by the German Federal Bureau of Labour. The fact that the data was collected for administrative purposes is an obvious advantage and makes the data particularly reliable. The IABS contains all workers in West-Germany who have had at least one employment spell eligible to the social security insurance scheme. As a result, included are all dependent employees in the private sector, i.e. about 80 percent

\footnotetext{
${ }^{16}$ IABS abbreviates Institut für Arbeitsmarket und Berufsforschung Sample.
} 
of total employment in West-Germany. Not included are: civil servants, selfemployed, unpaid family workers and people who are not eligible for benefits from the social security system. ${ }^{17}$

The event history data includes information on every change in working status distinguished into full-time work, part-time work, interruptions and unemployment. Interruptions indicate that the employer-employee relationship is on hold, yet the contract still valid. In this case no wage payments are made. Unemployment is reported in case of receipt of unemployment insurance or unemployment assistance. Every other status that does not fall in either of these categories results in a gap of the individual record of spells reported in the data. As a result interruptions reported for young workers can be used to identify maternity - or parental - leave for young females. Parental leave, as pointed out, is very exceptional for males. More generally, interruptions may be reported if a work is absent for a longer period of time due to health problems, for example. We assume that this does not apply in a significant number of cases of young females. In particular, we may not run into measurement error problems since we focus on the first interruption, that we interpret as the first birth. The IABS does contain a variable number of children that is generated on the basis of the tax cards. However, the quality of the variable is very poor for females, in particular, as it has also been admitted by the data producer. Hence, we refrain from using this variable. $^{18}$

$>$ From the IABS we generate a sample of young female workers whose postschooling work history is observed from the beginning. We distinguish three skill levels: unskilled and lowly skilled, the skilled, and graduates. Skilled workers

\footnotetext{
${ }^{17}$ For more details see Bender and Hilzendegen (1995).

${ }^{18}$ Calculation of mean number of children on the basis of this variable shows that it underestimates the number in a implausible way.
} 
are defined as those who have undertaken vocational training within the German dual system apprenticeship programme and 10 years of schooling (intermediate schooling degree). This is a vocational training programme that combines school and work-based educational programmes. This has been the main route into the labour market in Germany, in particular, since the 70's. 60-70 percent fall into this category. Unskilled and lowly skilled workers are defined as those having no additional training at all, or having shorter education than the skilled, that is less than 2 years of vocational training or college in addition to 10 years of schooling. ${ }^{19}$ Graduates are those with 13 or 12 years of schooling and who achieved a technical college degree, 3 to 4 years, or a university degree, 4-6 years.

In order to generate complete work histories we assume that graduates are not older than 23 in 1975, and everybody else is not older than 16 in 1975 . We generate the variable age at entry into first employment in order to control for unobserved heterogeneity in schooling. Wages in the IABS are reported on a daily basis and are highly reliable given that they are checked by both data collectors and employees. However, hours of work are not reported. By focusing on full-time workers, we mitigate this short-coming. In the empirical analyses, we present supplementary information from other data sources to scrutinize this aspect.

As a result of the sample design we observe complete work histories in the data that allows us to observe the accumulation process of human capital from the beginning, as well as wages. In our analyses, the main variables are the logarithmic wage, the work history variables work experience, total time out of work as well as time out of work segmented into unemployment, interruptions and other non-work periods, and variables measuring occupation, firm and skill. The wage

\footnotetext{
${ }^{19}$ Unfortunately, we cannot distinguish in the data whether individuals graduates after 9 or 10 years of schooling from the Hauptschule or Realschule.
} 
variable is the logarithm of the daily wage deflated by the CPI index. We define the variable time out of work as the total time not in salaried work, eligible to social security. It can be directly generated as the sum of days in unemployment, interruptions and non-work. Unemployment is reported in the data when individuals receive unemployment insurance. Unemployment insurance is granted to workers younger than 42 years for the maximum period of one year; unemployment assistance for infinity afterwards. As interruptions we label periods that capture maternity leave for women. The variable non work is a residual group that labels gaps between spells. These capture periods out of work due to other reasons than unemployment or maternity leave. ${ }^{20}$

\section{The econometric framework}

In this section we specify a statistical framework to summarise the evidence on earnings growth and earnings losses around first birth. This specification is intended to estimate short and long run wage effects preceding first birth as well as after returning to work.

The wage equation presented in this paper is based on the classical human capital model (see Becker (1964) and Mincer (1974)). Wages are determined by a simple model:

$$
\ln w_{i j t}=x_{i t} \beta+\delta D_{t}+\epsilon_{i j t}
$$

where

$$
\epsilon_{i j t}=\nu_{i}+f_{i j(t)}+u_{i j t}
$$

\footnotetext{
${ }^{20}$ This variable also incorporates, for example, further education, self-employment and employment not eligible to social security, i.e. jobs paid less than a lower social security threshold that was 350 German Mark per month in 1975 and 470 German Mark in 1990.
} 
We regress the logarithmic wage on a set of controls, $x_{i t}$, and dummy variables for each year, $D_{t}$. The subscript $i$ indicates the individual, $t$ time period and $j$ indicates the firm of employment. In the following we will estimate several specifications of this equation. The main variables included in all of them is work experience, interruption due to parental leave, occupation and firm fixed effects. The error term includes an individual specific component that captures unobserved individual specific characteristics, such as ability or motivation, a firm and individual specific component that may vary over time and measures the quality of a worker firm match, and an idiosyncratic shock with constant variance and zero mean.

In order to describe growth we transform equation (1) into first differences.

$$
\Delta l n w_{i j t}=\Delta x_{i t} \beta+\Delta \epsilon_{i j t}
$$

where

$$
\Delta \epsilon_{i j t}=\Delta f_{i j(t)}+\Delta u_{i j t}
$$

This leads to the elimination of all individual specific observed and unobserved components. Hence, the coefficients of the change in work experience, dummies for occupation change and firm change can be estimated. In the empirical analysis we will entirely focus of the growth equation.

The underlying behavioural model is the human capital theory model. ${ }^{21}$ In this framework we assume that the human capital is determined by the labour market experience, educational attainment and ability. We assume that the individual ability, preferences for working hard and productivity are constant over time and, therefore, wage growth is not affected by this. However, in the empirical analysis we will weaken this assumption.

\footnotetext{
${ }^{21}$ Becker (1964), Mincer (1974).
} 
The key parameters of interest in equation (5) are the return to work experience and the effect of interruption in order to describe the wage profile. From the human capital theory model it follows that coefficient of the experience variable is positive measuring returns to investment. By contrast, the coefficient of the interruption variable may be negative capturing depreciation of human capital. ${ }^{22}$ In this specification, we exclude tenure from the equation. Hence, we assume that only general human capital acquisition affects wages. This has the advantage to reduce the potential number of endogenous variables. Furthermore, in other studies it has been shown for Germany that returns to tenure may be small and negligible. ${ }^{23}$

Furthermore, mismatching may play a role in determination of the individual wages as well. Since we estimate the wage formation in the beginning of the labour market careers of young women, we expect these women to improve their match by changing firm. Suppose a worker is starting the career in a bad match. By changing job the worker can improve on the match. As a result, we would expect to find a higher wage in the new match, in comparison to the situation when the worker would have remained in the old match. Therefore, we model wage growth to be affected by occupation or firm changes. We include dummies for this type of behaviour.

A well-known problem is the endogeneity of the variables in the wage equation. Mainly, the problem arises because of sample selection. This implies that the error term in equation (3) is likely to be correlated with the variables of interest; in particular, the experience variable and the interruption variable. A commonly used approach in this type of model is the instrumental variable esti-

\footnotetext{
${ }^{22}$ Mincer and Polachek (1974).

${ }^{23}$ See Dustmann and Meghir (IFS, 1999). They show that tenure for skilled workers are very small.
} 
mation. Since labour supply is likely to be correlated with the change in work experience variables, we have to find instruments for labour supply. If it depends only on individual specific effects, estimation of the first difference equation is not affected. If it depends on time varying factors or if individual preferences change over time, however, then one needs to instrument for the change in work experience.

The richness of the IABS data provides us with a number of suitable instruments for labour supply. First, we use lagged levels of the work experience variable, and work experience variable squared, as instruments assuming that $E\left[x_{t-s} \mid\left(\Delta f_{i j(t)}+\right.\right.$ $\left.\left.\Delta u_{i j t}\right)\right]=0$, where $\mathrm{s}>1 .{ }^{24}$ Furthermore, we use age at entry into labour market, age and first differences in potential experience. Moreover, since we estimate wage equations for mothers, we use instruments particularly related to the labour force participation of mothers. That is we use information on the maternity leave protection period. In the sample period there have been a number of changes in the maternity leave system which provides us with an excellent instrument. As can be seen the duration of observed maternity leave is highly correlated with the official maximum duration of maternity leave protection.

\subsection{Empirical Model}

For the empirical implementation at this stage we specify wage growth equations for three different regimes: the pre-birth phase, the intermediate phase and the after birth phase. Forces that drive the wage profile within each phase may differ; e.g. the preferences for hard work may change when given birth. Therefore, by contrast to specifying one equation this approach has the advantage that it helps to pinpoint the mechanisms in more detail that lead to increasing and decreasing

\footnotetext{
${ }^{24}$ Arellano and Bond (1991).
} 
wages. Furthermore, we attempt to recover the structural key parameters of the model by instrumental variable estimation techniques. Other studies have pointed out the problem of weak instruments. By allowing the parameters to vary across these three phases we can exploit the instruments more efficiently.

\section{Pre-birth phase (the dip)}

The wage equation for the pre birth phase is specified as described in the previous section. In this model we include experience and experience squared in order to capture the decreasing return to experience. In line with Jacobson, LaLonde and Sullivan (1993) we allow wages to decline even before the interruption, by including dummy variables. ${ }^{25}$ We specify a dummy variable $B_{i t}^{k}=1$ if, in period $t$, worker $i$ had started an interruption period due to child birth $\mathrm{k}$ years later, where $-m<k<0$. In the estimations we will set $m=3$ since coefficients for $m>3$ are non-significant. ${ }^{26}$

$$
\Delta \ln w_{i j t}=\Delta x_{i t} \beta+\sum_{0>k>=-m} B_{i t}^{k} \delta_{k}+\delta \Delta D_{t}+\Delta \epsilon_{i j t} .
$$

Furthermore, in the application changing occupation and job can have a different impact if it is immediately before an interruption. The reason for doing this is because one of the explanations for the family gap is that women choose jobs or firms which pay less but are more family friendly. In order to investigate if women actually start choosing these jobs prior to the interruption, we consider that changing job or firm could have a negative impact on the wage process.

The instruments we are using for the experience variables in this phase are age, age at the entry at the labour market, first differences in potential experience,

\footnotetext{
${ }^{25}$ Different specifications has been tried but the dip seems to start around three years before the interruption.

${ }^{26}$ In the application we tested for significance of the coefficients when $\mathrm{m}>4$ which we could always reject.
} 
and experience and experience squared lagged two and three times.

\section{The interruption (the drop)}

To analyse the direct effect of the interruption due to maternity leave we specify an equation for wage changes around an interruption. If human capital depreciates while not working on the job ${ }^{27}$, then an interruption following the birth of the child may induce a drop in wages. To investigate this hyposthesis we include the duration of maternity leave as a regressor. If the depreciation of the human capital is correlated with the duration of the interruption, we expect wage growth to be negatively affected by the duration of maternity leave. The wage equation is similar to the previous one except that we add the duration of maternity leave, $M_{i t}$ :

$$
\Delta \ln w_{i j t}=\ln w_{i j a f t e r}-\ln w_{i j \text { before }}=\Delta x_{i t} \beta+\tau M_{i t}+\Delta \epsilon_{i j t}
$$

In this phase both the duration of maternity leave and the experience variables are likely to be endogenous. The instruments for experience and experience squared used in this phase are age, age at the entry at the labour market, first differences in potential experience, and experience and experience squared lagged two and three times. For the duration of maternity variable we use the policy changes in the maximum period of parental leave as an instrument.

\section{The post-birth phase (the recovery)}

In the post birth phase we estimate a wage equation for women who had one interruption due to maternity leave. We limit the sample period only to cover the period between the first interruption and the potential second interruption. For the after birth phase, we specify a dummy variable accordingly, that is $B_{i t}^{k}=1$

\footnotetext{
${ }^{27}$ Mincer and Polachek (1974).
} 
if, in period $t$, worker $i$ had started an interruption period due to child birth $\mathrm{k}$ years earlier, where $0<k<m .{ }^{28}$

$$
\Delta \ln w_{i j t}=\Delta x_{i t} \beta+\sum_{0<k<=m} B_{i t}^{k} \delta_{k}+\delta D_{t}+\Delta \epsilon_{i j t} .
$$

We then proceed as described above and estimate the equation by instrumental variable estimation.

We focus in the estimation on first birth. The model is estimated for female workers for whom we only observe one interruption spell. Hence, we exclude effects of second, and further births. ${ }^{29}$ In order to evaluate results further we borrow from the program evaluation literature. We define control groups: females who have no children. This is an approach that has also been used in the displaced worker literature. ${ }^{30}$

\section{Estimation Results}

In this paper, we mainly focus on women who are having children in the observation period. The reason for focusing on this group is because that women who remain childless might have different unobserved characteristics than women who have children. We acknowledge that some of the women we exclude might have their first children after the observation period is finished and thereby we tend to oversample women giving birth earlier. However, the average age of giving birth in this sample is for the unskilled/lowly skilled: 24.6 , skilled/apprentices 25.3 and for graduated 30.3. In order to investigate whether there are strong differences we also consider a sample of women who remain childless. We return to this later.

\footnotetext{
${ }^{28}$ In the application we tested for significance of the coefficients when $\mathrm{m}>4$ which we could always reject.

${ }^{29}$ Hence, we avoid getting in fertility models and complete fertility problems.

${ }^{30}$ Jacobson, LaLonde, Sullivan (AER, 1993).
} 
We structure the analysis of wage effects around the first birth by looking, first, at the pre-birth phase, second, at the interruption phase, and, third, at the post birth phase. Hence, in contrast to Jacobson, LaLonde and Sullivan (1993) analyse each of the three wage effects separately.

\subsection{Pre-birth phase (The dip)}

In this analysis we examine the wage process before the first labour market interruption due to a maternity leave spell, by using the model described in the previous section. In Table 2 the estimation results are reported.

In general the results seem plausible and we find that the return to experience is positive but decreasing in the level of experience. The estimated return to experience is highest for graduates and lowest for unskilled. The return from increasing the level of experience from two to three years ${ }^{31}$ is for unskilled/lowly skilled 2.0 percent, skilled/apprentices 3.7 percent and graduates 6.5 percent. For comparison, Dustmann and Meghir (1998) find that the average return to experience for young male Germans with completed apprenticeship training is 2.7 percent, while in our sample the average return to experience for individuals with apprenticeship training is 3.3 percent. Furthermore, we find that changing the firm has a positive impact on wage growth for the unskilled and skilled. This result is in accordance with the idea that early in the career workers improve their match by changing firm. For graduates the effect is negative but insignificant. On the other hand, we find no evidence of the effect of changing occupation. It suggests that occupational specific human capital only plays a minor role in the determination of the wages.

\footnotetext{
${ }^{31}$ For this sample, the average level of experience for all education groups is between two and three years.
} 
In the estimation we have included dummy variables for the three years prior to the interruption. Except for graduates the estimates for the dummies are negative indicating that wages start indeed to decrease three years prior to the interruption. The estimates suggest that for unskilled and skilled women wages decline by about 2.2 percent the year before the interruption. ${ }^{32}$ This confirms that there is a small dip in wages just before the interruption. This is in contrast to the study by Waldfogel $(1998)^{33}$, where she could not find any evidence for a decline in wages prior to an interruption using data from the US. Moreover, we find that skilled women do not improve their wages by changing firm if it is within the three years prior to the interruption. In general, wages increase when changing firm. An explanation for this is that women prior to giving birth choose jobs that pay less but instead offer a family friendly work environment. For unskilled and graduates no effect of changing firm prior to the interruption is found.

\subsubsection{The control group}

In order to evaluate whether women with and without children face different wage processes, we present in this section estimation results for a sample of women who remain childless in the observation period and compare them to the previous results. ${ }^{34}$ We find that the group who remains childless have higher entry wages; for unskilled/lowly skilled women who remain childless earn on average 2.0 percent more than women who later have children. For skilled workers the difference is 5.8 percent and for graduates 3.0 percent. This suggests that even before the

\footnotetext{
${ }^{32}$ There are only small losses two and three years prior to the interruption.

${ }^{33}$ For further details see Wagelfogel (1998), footnote 13.

${ }^{34}$ As mentioned earlier, we cannot exclude the possibility that women in this sample give birth later than 1995 when the observation window ends.
} 
interruption, groups differ. ${ }^{35}$. This provides evidence for the hypothesis that part of the family gap is due to heterogeneity. To examine how wages develop we estimate a wage equation. The wage equation is the same as the previous one except that dummies indicating the years prior to the interruption drop out.

The estimation results in Table 3 show that the return to experience is positive and highest for graduates and lowest for unskilled. Furthermore, the results also show that the return to experience is lower for all education groups compared to the return of childless women who are going to give birth later. This, somehow surprising result, indicates that women who are going to give birth start with a lower entry wage but have a higher return to experience. Another difference between the two groups is that for women who remain childless there is a negative effect of changing occupation. The return from changing firm is almost the same for the two groups. However, since women in the control group are much more likely to change firm than women in their pre-birth period this means that the gap between these two groups persists.

\subsection{The interruption (The drop)}

To analyse the direct impact of the interruption we compare the wages in the last spell before the interruption due to maternity leave and the wages in the first spell after the interruption. However, since not all women in our sample return to work after giving birth we start by providing summary statistics on this aspect.

\footnotetext{
${ }^{35}$ A similar result is found for the US. Lundberg and Rose (2000) found the difference to be nine percent.
} 


\subsubsection{Return to work}

In figure 2 the average probability of return to work is shown for the sample period. The figure shows that the probability of return within three years after the interruption was about 70 percent in the beginning of the $80 \mathrm{~s}$ and has been declining to about 50 percent in the beginning of the $90 \mathrm{~s}$. The graph also shows that until the mid 80s more than half of women returned within the first year after the interruption and only very few return between the second and the third year after the interruption. Moreover, the figure also shows that the major reforms of the maternity leave system in 1986 and 1991 have had an impact on the probability of returning and the length of the maternity leave. ${ }^{36}$ From 1986 onwards, there is a tendency that women take longer maternity leave ${ }^{37}$. This trend has been reinforced after 1991. In the following we use for identification of the wage loss due to interruption the fact that the duration of maternity leave is affected by the policy changes.

\subsubsection{The drop}

For those women who return to work we can compare wages in the last spell before the interruption with wages in the first spell after the interruption. It turns out that more than 50 percent receive a lower wage when they return to work. The average loss in wages is reported in Table 4 . In the first row of Table 4 the average loss for the different education groups is reported. The numbers show clearly that unskilled/lowly skilled have a substantially smaller loss than the remaining groups; that is 19 percent loss compared to 32 percent. When focusing on the group of women who return to the same firm after parental leave has ended

\footnotetext{
${ }^{36}$ Similar results were reported in Ondrich, Spiess and Yang (1996).

${ }^{37}$ Fewer women return within the first year after 1986, but the fraction returning within three years is almost constant.
} 
the loss is a bit lower. However, even for the group of women who return to the same firm and the same occupation the loss is still approximately 15 percent for the lowly skilled and more than 25 percent for skilled and graduates. Since we compare daily wages the drop may partly be due to a reduction in working hours. However, we are only considering full time employment which means that these women should at least work 35 hours per week both before and after the interruption. Unfortunately we do not have access to information about the numbers of working hours in the IABS sample. So it is difficult to tell exactly how much a reduction in hours contributes to the loss. If the entire loss is due to a reduction in hours this means that unskilled women should have been working about 41 hours on average before they give birth while for skilled and graduates it would be 46 hours. We will investigate this aspect more using an alternative data source.

In the following we decompose the loss due to different factors. As shown in the table changing firm and job in connection with an interruption seems to have an impact. Furthermore we include the duration of maternity leave (in years). Finally, the nature of the data implies that wage growth is associated with different length of spells. For that reason we also include experience and experience squared. In Table 5 the results are reported for a regression where we do not use instruments.

The estimation results show that changing firm and occupation has a strong negative effect on wages. A similar result was found for the US (see Waldfogel (1998)) and for Canada (see Phipps, Burton and Lethbridge (2001)). This suggests that staying with the same employer may act as a kind of insurance against income loss of mothers. We also find that the duration of the interruption has a negative impact. This provides evidence for the hypothesis concerning human capital depreciation (see Mincer and Polachek (1974)). 


\subsubsection{Evidence from other data sources}

In order to provide more knowledge about the huge wage loss, we exploit alternative data sources. Using survey data ${ }^{38}$ we obtain additional information about the number of working hours in the Western German states. In this data set both the official and the actual working hours are stated for 1995. We select a sample of women aged 20-40 and who all report that they work full time (the official working hours are at least 35 hours per week). Then, we compare the actual working hours of those aged 20 to 40 who have children with those without children. On average the sample without children work 40.1 hours per week ${ }^{39}$, while those with children work 39.1 hours per week $^{40}$. Although the women without children work one hour less per week, this can only explain a decrease in the daily wages on 2.5 percent. This indicates strongly that only a small part of the wage loss is due to a reduction in working hours.

\subsection{The post birth phase (The recovery)}

As shown in the previous section women are taking a huge wage cut when they return to work after maternity leave. In this section we analyse the wage process after the interruption to see if these women are recovering when they get back. We analyse how wages develop in the period after first birth and before second birth, if such is taking place.

\footnotetext{
${ }^{38}$ Data Survey is collected by the IAB, Nürnberg and distributed by the Central Unit Archive in Cologne (Zentralarchiv):Erwerbswünsche und Erwerbsverhalten von Frauen in Ost und Westdeutschland, 1995 (in English: Desired Work and Working Behaviour of Women in East and West Germany in 1995)

${ }^{39}$ This number is the average number of working hours based on 480 childless women.

${ }^{40}$ This number is the average number of working hours based on 332 women with children.
} 
In Table 6 instrumental variable estimation results of the wage growth equation after the first interruption are shown. Firstly, the results suggest that the return to experience is much higher after the interruption. This means that there is evidence for that women are recovering their former wage level after the interruption. It also seems to be the case that those education groups with the largest loss also have the highest return to experience afterwards. In this life stage changing firm seems not to have an impact on wages, while changing occupation has a negative impact; women loose between one and four percent by changing occupation. Compared to the control group estimates shown in Table 3 this loss seems a bit larger. Furthermore, we find only a very small and insignificant dip before the second birth.

\section{Concluding remarks}

In this paper we investigate wage effects for women around first birth. Simple descriptives on wages for a sample of women in their $20 \mathrm{~s}$ to 40 s reveal that shortly before the interruption a dip in the wage profile is observed. On return to work, that is after exiting the parental leave period, wages drop further by approximately 15 to 20 percent. In our analysis we want to shed light upon what explains this huge drop that is out of range of estimates on losses from other types of interruptions, such as unemployment. We set up a simple wage regression framework. The key parameters of interest are the return to work experience and the effect of the interruption itself. For identification we make use of a rich set of instruments that includes the use of the policy variable that measures the maximum duration of parental leave.

The main results are that the dip is in fact very small. The large (reduced form) 'dip' effect can be explained by firm changes immediately before the interruption. 
This seems plausible and in line with the policy that gives strong incentives to remain with the employer before going on parental leave. Only this behaviour ensures a secure work place afterwards. In contrast to the dip the large drop seems to be a very robust result. The consistent parameter estimate suggests that the loss is larger than 11 percent for each year of interruption for the unskilled, 16 percent for skilled and only 4 percent for graduates. This is consistent with high employment rates of high skilled workers with children younger than 6 , and 10 to 20 percentage points lower ones for medium and low skilled workers (OECD, 2001, p.134.).

Given recent demographic trends that are disadvantageous for employment growth, and the competition for highly qualified workers family friendly policies seems to become more and more important in order to ensure that working careers and children are compatible. With few exceptions, this is mostly an issue for women. The parental leave policy that is a major pillar of these policies in Germany and regulated by the government is claimed to be one of the most generous in international comparison. Mainly, this is based on the fact that since the early $90 \mathrm{~s}$ parental leave for a period of up to 3 years can be taken, and at the same time the employment contract with firm is put on hold, instead of being layed off. This study illustrates that at the same time this coincides with large costs for the individual worker. This in turn may have a negative impact on labour supply, and, hence, explain low female labour force participation rates.

\section{References}

[1] Ashenfelter, Orley, (1978), Estimating the Effect of Training Programs on Earnings. Review of Economics and Statistics, 60(1), pp. 47-57. 
[2] Albrecht, James W., Edin, Per-Anders, Sundström, Marianne, Vroman, Susan B., (1999), Career Interruptions and Subsequent Earnings: A reexamination using Swedish Data, Journal of Human Resources, 34(2), pp. 294-311.

[3] Arellano, Manuel, and Stephen Bond (1991): Some tests of specification for panel data: Monte Carlo Evidence and an application to employment equations, Review of Economic Studies, 58(2), pp.277-297.

[4] Becker, Gary (1964): Human capital - A theoretical and empirical analysis with special reference to education, Chicago University Press, 3rd edition, 1993.

[5] Becker, Gary (1985): Human Capital, Effort, and the Sexual Division of Labor, textitJournal of Labor Economics, 3(1), pt.2, pp.S34-S58.

[6] Blau, Francine, and Lawrence M. Kahn (1995): The gender earnings gap: Some international evidence, in: Differences and changes in wage structures, Freeman and Katz, editors, National Bureau of Economic Research, Comparative Labor Market Series, University of Chicago Press.

[7] Datta Gupta, Nabanitta, Smith, Nina, (2000), Children and Carrer interruptions: The Family Gap in Denmark. CLS Working paper 00-03 2000.

[8] Dustmann, Christian and Costas Meghir (1999), Wages, Experience and Seniority, Institute for Fiscal Studies, Working Paper 99/1.

[9] Gustafsson, Siv, Bruyen-Hundt, M. (1991), Incentives for Women to Work: A comparison between The Netherlands, Sweden and West Germany, Journal of Economic Studies, 18(5/6), pp. 30-65. 
[10] Gustafsson, Siv, Bruyen-Hundt, M. (1996), Women's labor force transitions in connection with childbirth: A panel data comparison between Germany, Sweden an Great Britain, Journal of Population Economics, pp.223-246.

[11] Jacobson, Louis, Robert J. LaLonde and Daniel G. Sullivan (1993): Earnings Losses of Displaced Workers, American Economic Review, 83(4), pp. 685-709.

[12] Joshi, Heather; Paci, Pierella; Waldfogel, Jane, (1999): The Wages of Motherhood: Better or Worse?, Cambridge Journal of Economics, 23(5), pp. 54364.

[13] Kunze, Astrid (2001): Gender Differences in Entry Wages and Early Career Wages, mimeo, IZA Bonn.

[14] Lundberg, S.; and E. Rose (2000): Parenthood and the earnings of married men and women, Labour Economics, 7(6), pp.689-710.

[15] Mincer, Jacob, Polachek, Solomon, (1974): Family Investments in Human Capital: Earnings of women. Journal of Political Economy, 82(2), (supplement), pp. S76-S108.

[16] Mincer, J., and S. Polachek (1978): Women's earnings reexamined, The Journal of Human Resources, 13(1), pp.118-134.

[17] Nielsen, Helena Skyt, Marianne Simonsen and Mette Verner (2001): Earnings effects of career interruptions in a model with endogenous sector choice, mimeo.

[18] OECD (1995): Employment Outlook, Chapter 5: Long-term leave for parents in OECD countries, July 1995.

[19] OECD (2001): Employment Outlook, Chapter 4: Balancing work and family life: Helping parents into paid employment, June 2001. 
[20] Ondrich,Jan; Spiess,C.Katharina; Yang,Qing, (1996): Barefoot and in a German Kitchen: Federal Parental Leave and Benefit Policy and the Return to Work after Childbirth in Germany. Journal of Population Economics, 9(3), pp. $247-66$.

[21] Ondrich, J; C.K. Spiess, Q. Yang and G.G Wagner (1999): Full time or part time? German parental leave policy and the return to work after childbirth in Germany, Research in Labor Economics, 18, pp.41-74.

[22] Phipps, Shelley, Peter Burton and Lynn Lethbridge (2001): In and out of labour market: Long-term income consequences of child-related interruptions to women's paid work, Canadian Journal of Economics, 34(2), pp. 411-429.

[23] Ruhm, Christopher J., (1998): The Economic Consequences of Parental Leave Mandates: Lessons From Europe, The Quarterly Journal of Economics, 113(1) pp. 285-317.

[24] Waldfogel, Jane, (1998): The Family Gap for Young Women in the United States and Britain: Can Maternity Leave Make a Difference? Journal of Labor Economics, 16(3), pp. 505-45.

[25] Weiss, Yoram, Gronau, Reuben (1981): Expected Interruptions in the Labour Force Participation and Sex-Related Differences in Earnings Growth. Review of Economic Studies, 48, pages 607-619. 


\section{A Appendix: Tables and Figures}

\section{A.1 Appendix}

Table 1: German maternity/parental leave policy, 1968-2001

\begin{tabular}{|c|c|c|c|}
\hline $\begin{array}{l}\text { children } \\
\text { born } \\
\text { since... }\end{array}$ & $\begin{array}{l}\text { maternity } \\
\text { protection } \\
\text { months }\end{array}$ & $\begin{array}{l}\text { protected leave } \\
\text { in in months }\end{array}$ & $\begin{array}{l}\text { entitlement to } \\
\text { Parental Leave } \\
\text { benefits (from } \\
6 \text { th month on- } \\
\text { wards means } \\
\text { tested) }\end{array}$ \\
\hline. $.1968^{* * * 4}$ & 2 & 0 & 0 \\
\hline. $.1979^{4}$ & 2 & 4 & 6 \\
\hline. $.1986^{5}$ & 2 & 8 & 10 \\
\hline. .1 .1 .1987 & 2 & 10 & 12 \\
\hline ..1.7.1989 & 2 & 13 & 15 \\
\hline. .1 .7 .1990 & 2 & 16 & 18 \\
\hline ..1.1.1992 & 2 & 34 & 18 \\
\hline ..1.1.1993 & 2 & 34 & 24 \\
\hline ..1994 & 2 & 34 & 24 \\
\hline. .1996 & 2 & 34 & 24 \\
\hline ..1.1. $2001^{* *}$ & 2 & 34 & 24 \\
\hline
\end{tabular}

Notes: Periods are counted from delivery of the child onwards. One may note that the maternity protection period starts already 6 weeks before delivery. 
Table 2: Wage growth before the interruption

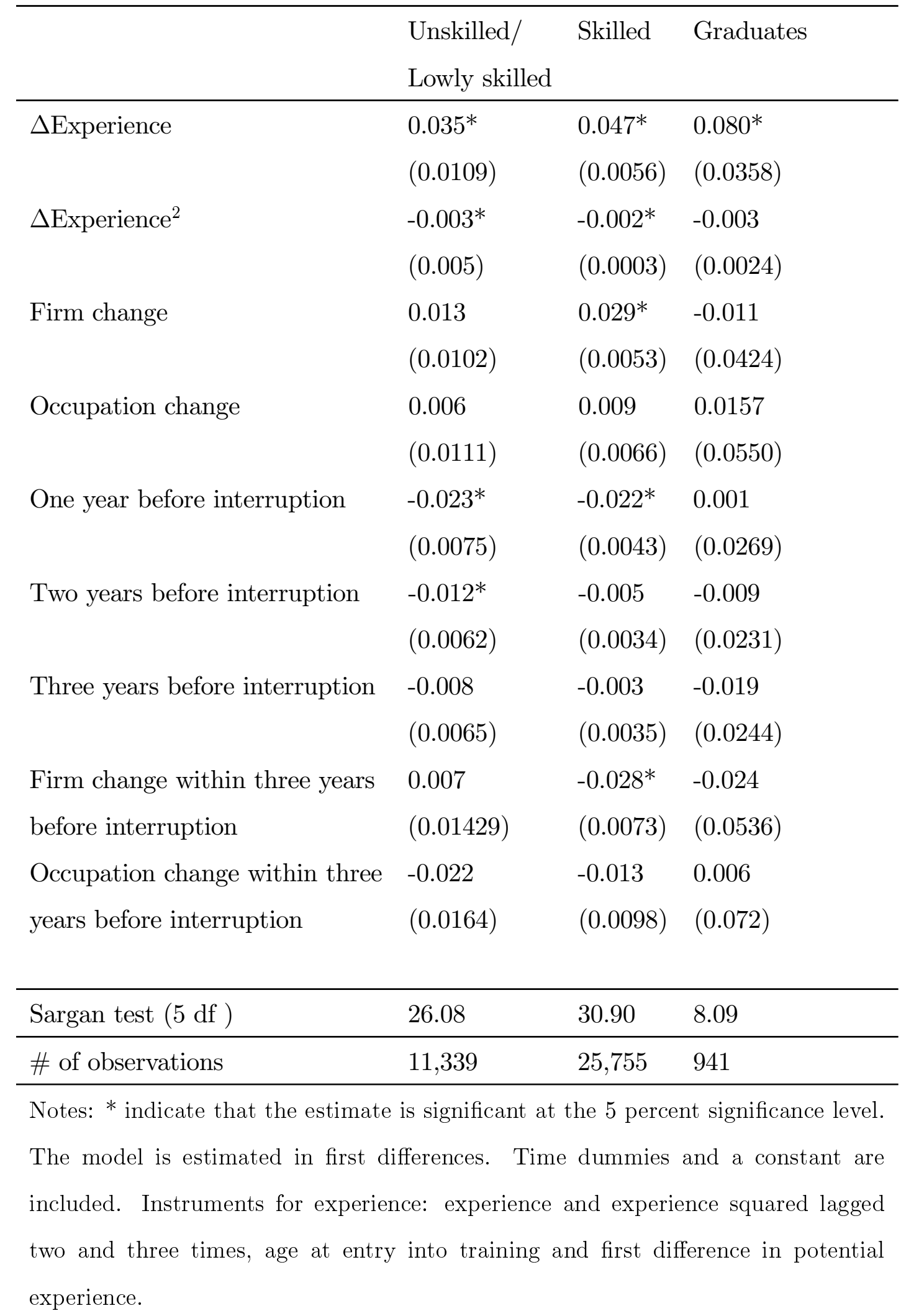


Table 3: Wage growth of childless women with no interruption

\begin{tabular}{llll}
\hline & $\begin{array}{l}\text { Unskilled/ } \\
\text { Lowly skilled }\end{array}$ & Skilled & Graduates \\
\hline$\Delta$ Experience & $0.013^{*}$ & $0.025^{*}$ & $0.036^{*}$ \\
& $(0.0067)$ & $(0.0033)$ & $(0.0139)$ \\
$\Delta$ Experience ${ }^{2}$ & $-0.002^{*}$ & $-0.002^{*}$ & $-0.001^{*}$ \\
& $(0.002)$ & $(0.0001)$ & $(0.0053)$ \\
Firm change & 0.010 & $0.022^{*}$ & -0.004 \\
& $(0.004)$ & $(0.0025)$ & $(0.0106)$ \\
Occupation change & $-0.022^{*}$ & $-0.0144^{*}$ & -0.0167 \\
& $(0.004)$ & $(0.0028)$ & $(0.0131)$ \\
\hline Sargan test $(5$ df $)$ & 25.59 & 93.848 & 18.48 \\
\hline \# of observations & 36,551 & 78,207 & 4,865 \\
\hline Notes: $*$ indicate that the estimate is significant at the 5 percent significance level. \\
The model is estimated in first differences. Time dummies and a constant are \\
included. Instruments for experience: experience and experience squared lagged \\
two and three times, age at entry into training and first difference in potential \\
experience.
\end{tabular}


Figure 2:

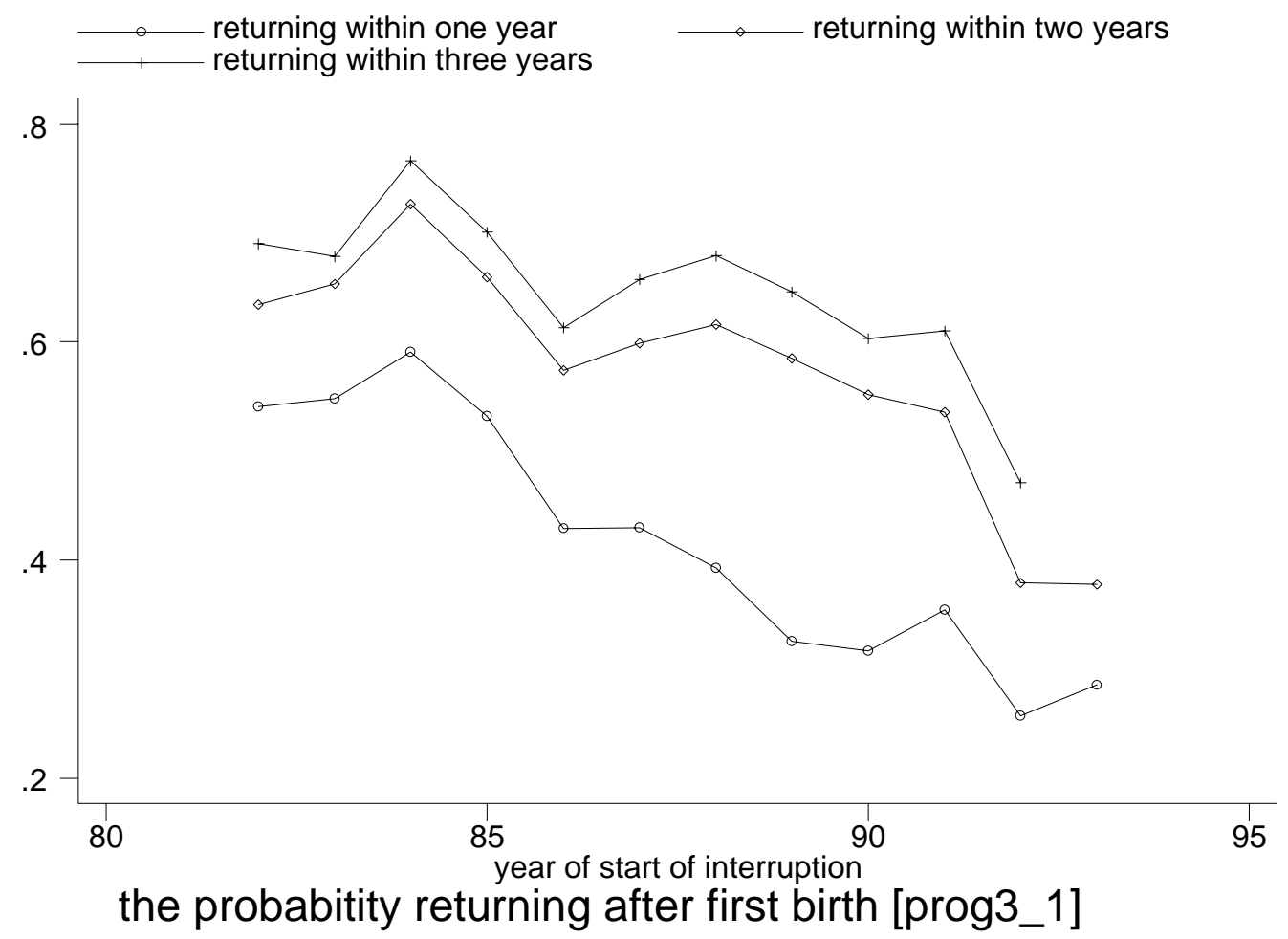


Table 4: The average loss (in percent) due to the interruption

\begin{tabular}{llll}
\hline & $\begin{array}{l}\text { Unskilled/ } \\
\text { Lowly skilled }\end{array}$ & Skilled & Graduates \\
\hline All & 18.7 & 32.1 & 31.5 \\
& $(2185)$ & $(4126)$ & $(260)$ \\
Staying in the same firm & 16.0 & 29.5 & 27.2 \\
& $(1468)$ & $(2778)$ & $(187)$ \\
Staying in the same firm & 15.4 & 29.3 & 27.4 \\
and in the same occupation & $(1391)$ & $(2656)$ & $(185)$ \\
\hline Notes: The loss is calculated as mean of the differences between the log wages in \\
the last spell before the interruption and the first spell after the interruption. The \\
figures in parentheses are the number of observations.
\end{tabular}


Table 5: The loss due to the interruption

\begin{tabular}{llll}
\hline & $\begin{array}{l}\text { Unskilled } / \\
\text { Lowly skilled }\end{array}$ & Skilled & Graduates \\
\hline$\Delta$ Experience & $0.133^{*}$ & $0.194^{*}$ & 0.039 \\
$(0.0418)$ & $(0.0 .0315)$ & $(0.135)$ \\
$\Delta$ Experience $^{2}$ & $-0.020^{*}$ & $-0.020^{*}$ & 0.002 \\
& $(0.0027)$ & $(0.0020)$ & $(0.0098)$ \\
Firm change & $-0.078^{*}$ & -0.037 & -0.064 \\
& $(0.0337)$ & $(0.0229)$ & $(0.1077)$ \\
Occupation change & -0.026 & $-0.0373^{*}$ & -0.167 \\
& $(0.0358)$ & $(0.0262)$ & $(0.1314)$ \\
Duration of & $-0.111^{*}$ & $-0.160^{*}$ & -0.048 \\
interruption & $(0.0279)$ & $(0.0199)$ & $(0.1018)$ \\
\hline \# of observations & 2185 & 4126 & 260 \\
\hline Notes: * indicate that the estimate is significant at the 5 percent significance level. \\
The model is estimated in first differences (first spell after interruption - last spell \\
before interruption).
\end{tabular}


Table 6: Wage growth after the interruption

\begin{tabular}{|c|c|c|c|}
\hline & \multicolumn{3}{|l|}{ Lowly skilled } \\
\hline \multirow[t]{2}{*}{$\Delta$ Experience } & 0.098 & $0.112^{*}$ & 0.170 \\
\hline & $(0.063)$ & $(0.051)$ & $(0.094)$ \\
\hline \multirow[t]{2}{*}{$\Delta$ Experience $^{2}$} & $-0.002^{*}$ & $-0.002^{*}$ & -0.002 \\
\hline & $(0.001)$ & $(0.0008)$ & $(0.0159)$ \\
\hline \multirow[t]{2}{*}{ Firm change } & 0.005 & 0.011 & 0.032 \\
\hline & $(0.028)$ & $(0.0232)$ & $(0.034)$ \\
\hline \multirow[t]{2}{*}{ Occupation change } & -0.038 & $-0.034^{*}$ & -0.012 \\
\hline & $(0.0154)$ & $(0.0127)$ & $(0.0382)$ \\
\hline \multirow{2}{*}{$\begin{array}{l}\text { One year before } 2 \text { nd } \\
\text { interruption }\end{array}$} & -0.008 & -0.005 & -0.006 \\
\hline & $(0.0168)$ & $(0.0124)$ & $(0.0307)$ \\
\hline Sargan test (9 df ) & 25.75 & 17.28 & 4.90 \\
\hline \# of observations & 5,364 & 7,853 & 605 \\
\hline \multicolumn{4}{|c|}{ Notes: * indicate that the estimate is significant at the 5 percent significance level. } \\
\hline \multicolumn{4}{|c|}{$\begin{array}{l}\text { The model is estimated in first differences. Time dummies and a constant are } \\
\text { included Instruments for experience: experience and experience squared lagged two }\end{array}$} \\
\hline
\end{tabular}




\section{A.2 Appendix}

Table A2.1: Empirical studies of the family gap

\begin{tabular}{|c|c|c|c|c|}
\hline Study & Waldfogel, 1998 & \multicolumn{2}{|c|}{$\begin{array}{l}\text { Joshi, Paci and } \\
\text { Waldfogel, } 1999\end{array}$} & $\begin{array}{l}\text { Phipps, Burton and } \\
\text { Lethbridge, } 2001\end{array}$ \\
\hline Data & Panel & \multicolumn{2}{|c|}{ Cross sections } & $\begin{array}{l}\text { Cross sections with } \\
\text { retrospective information }\end{array}$ \\
\hline Country & US & \multicolumn{2}{|l|}{ US and UK } & Canada \\
\hline Dependent variable & log wage & \multicolumn{2}{|l|}{ log wage } & log income \\
\hline Estimation of family gap & Children & \multicolumn{2}{|l|}{ Children } & Interruptions \\
\hline Main explanatory var. & $\begin{array}{l}\text { Experience } \\
\text { and education }\end{array}$ & \multicolumn{2}{|c|}{$\begin{array}{l}\text { Experience } \\
\text { and education }\end{array}$} & $\begin{array}{l}\text { Experience and } \\
\text { duration of interruptions }\end{array}$ \\
\hline Estimation method & $\begin{array}{l}\text { Fixed effect/ } \\
\text { First differences }\end{array}$ & \multicolumn{2}{|c|}{ Heckman and OLS } & OLS \\
\hline Study & \multicolumn{2}{|c|}{$\begin{array}{l}\text { Albrecht, Edin, Sundströ m } \\
\text { and Vroman, } 1999\end{array}$} & \multicolumn{2}{|c|}{$\begin{array}{l}\text { Datta Gupta and Smith } \\
2001\end{array}$} \\
\hline Data & \multicolumn{2}{|c|}{$\begin{array}{l}\text { Cross sections and } \\
\text { Panel data }\end{array}$} & \multicolumn{2}{|c|}{ Panel data } \\
\hline Country & \multicolumn{2}{|c|}{ Sweden } & \multicolumn{2}{|c|}{ Denmark } \\
\hline Dependent variable & \multicolumn{2}{|c|}{ log wage } & \multicolumn{2}{|c|}{ log wage } \\
\hline Estimation of family gap & \multirow{2}{*}{\multicolumn{2}{|c|}{$\begin{array}{l}\text { interruptions } \\
\text { experience, education, } \\
\text { children and interruption var. }\end{array}$}} & \multirow{2}{*}{\multicolumn{2}{|c|}{$\begin{array}{l}\text { Children } \\
\text { experience, education, }\end{array}$}} \\
\hline Main explanatory var. & & & & \\
\hline Estimation method & \multicolumn{2}{|c|}{ OLS/Fixed effect } & \multicolumn{2}{|c|}{$\begin{array}{l}\text { Randon or Fixed effect } \\
\text { and Heckman }\end{array}$} \\
\hline
\end{tabular}

In table A2.1 the studies examining the family gap have been summarised. These studies provide measures of the family gap. In all studies a wage equation is estimated, except for in Phipps, Burton and Lethbridge, 2001, where an equation for income was estimated. The data used in these studies are either panel data or cross sections and therefore the estimation methods also vary. However, only two studies are dealing with the sample selection bias, arising from the fact that only for individuals working wages are observed. Furthermore, studies differ in their approach to estimate the family gap. While in some of the studies the family gap is measured by estimating the impact of children others estimate the impact of an interruption due to maternity leave. 